Федотова Надежда Николаевна - доктор социологических наук, профессор кафедры социологии Московского государственного института международных отношений (Университета) Министерства иностранных дел Российской Федерации. Адрес: 119454, Россия, г. Москва, пр. Вернадского, д. 76. Тел.: +7 (495) 434-94-26. Эл. адрес: nnfedotova@rambler.ru

Fedotova Nadezhda Nikolayevna, Doctor of Sociology, Professor, Department of Sociology, Moscow Institute of International Relations (MGIMO University), Ministry of Foreign Affairs of the Russian Federation. Postal address: 76, Vernadskogo Ave., Moscow, Russian Federation 119454. Tel.: +7 (495) 434-94-26. E-mail: nnfedotova@rambler.ru

DOI10.17805/zpu.2017.4.8

\title{
Современный язык: «вместилище культуры» или форма социокультурной адаптации?
}

\author{
А. В. КОСТИНА \\ МОСКОВСКИЙ ГУМАНИТАРНЫЙ УНИВЕРСИТЕТ
}

В статье рассматриваются новые языковые явления, формирование которых обусловлено развитием научно-технических, социальных, экономических, культурных факторов. Это сетевая литература и ее новые формы и жанры, выполняющие различные функции начиная от языковых, эстетических, познавательных до социальных и коммуникативных. Автор показывает, что сегодня понятие «литература» означает новое явление, прежде всего связанное с возможностью свободного публичного высказывания. Показано, что на изменение социокультурной среды моментально реагирует язык, в том числе посредством создания не только целой системы неологизмов, но и принципиально новых языковых форм.

Названия новых жанров сетевой литературы, как правило, представляют собой транскрипции англоязычных названий. В силу своей сжатости в пространстве и во времени она апеллирует преимущественно к тем ситуациям, которые выступают как наиболее сильные раздражители. Сетевая литература использует такие свойства Сети, как нелинейность и опора на гиперссылки, благодаря которым образуется гипертекст; интерактивность, позволяющую вторгаться в текст, дописывать его или, по крайней мере, разгадывать.

Все тексты, выложенные в Сеть, можно разделить на две группы. Первые созданы по законам линейного текста и могут быть расположены на определенных ресурсах - библиотеках, журналах и т. д. Вторая группа текстов создана совершенно по другим законам, которые определяются особенностями строения самой Сети, главными признаками которой выступают создание киберпространства и нового времени - вневременного.

Главное качество сетевой литературы - социальность. Именно сетевая коммуникация выступает как полноценный заменитель реального, живого общения, осуществляющегося непосредственно. Социальные группы в Сети различны по численности; входящие в эти сообщества преследуют разные цели; они различны по степени включенности в сетевую жизнь. Отмечается существенное влияние сетевой культуры на культуру в целом. Сетевые формы коммуникации соответствуют потребностям и ожиданиям людей и отражают те доминантные смыслы культуры, которые, складываясь в сетевых сообществах, распространяются в обществе в целом.

Ключевые слова: литература; язык; культура; социокультурная ситуация; сетевая литература; глобализация; Интернет; информационное общество; Сеть 


\section{ВВЕАЕНИЕ}

Начиная с научно-технической революции XIX в. человечество привыкло к новым научным открытиям и техническим инновациям, которые радикально изменяют повседневную жизнь каждого человека. Конечно, научные открытия столь существенно преобразили картину мира человека XX в., что стали восприниматься как нечто естественное, в том числе испытания адронного коллайдера, дискурс о черных дырах, темной материи и пр., планы по полету на Венеру и Марс, проекты по ликвидации катастроф, связанных с приближающейся сменой земных полюсов и пр. Мы привыкли к смене поколений техники через каждые два-три года, к полифункциональности средств связи и неисчерпаемым возможностям интернет-технологий. Аля нас становится обыденностью замена человеческого труда работой компьютеров и роботов. В 2016 г., по сообщениям СМИ, в США в Технологическом институте Ажорджии на парах по искусственному интеллекту профессор пользовался помощью ассистентки Ажил Ватсон. При этом студенты не заметили, что она - искусственный интеллект на платформе IBM Watson (Рыбаков, 2016: Электронный ресурс).

Одним из наиболее важных факторов, определивших трансформации современного языка, безусловно, является распространение экранной культуры и ее превращение в доминирующую языковую и культурную форму. Здесь нужно отметить не только появление новых способов фиксации и трансляции информации, но и образование новой интернациональной языковой среды. Связанная с сетевой культурой - культурой Интернета и социальных сетей и сообществ, - эта языковая среда демонстрирует процессы трансформации национальной специфики мышления под влиянием унифицированного англоязычного новояза. Сегодня распространение английского языка становится условием распространения универсального образа жизни - английским языком пользуются сегодня в качестве средства общения около 1,5 млрд людей, на английском во Всемирной компьютерной сети хранится более $90 \%$ всей информации, большинство компьютерных программ и инструкций к ним написаны на английском, английский становится языком мировых технических и научных периодических изданий, языком электроники, медицины и космических технологий. Сегодня мы все хотя и живем локально, но говорим на глобальном языке. Примером таких «языковых мутантов» являются «денглиш» в Германии и «синглиш»в Сингапуре.

Цель данной статьи - рассмотреть сетевые языковые практики и обосновать функцию современного языка, направленного не только на передачу информации и установление понимания, но и - преимущественно - на социальное общение.

\section{ТЕХНОАОГИЧЕСКАЯ РЕААЬНОСТЬ И РЕАЯЬНОСТЬ ЯЗЫКА}

Проблема влияния технологической реальности на текст культуры на первый взгляд также представляется абсолютно ясной. И это показали по крайней мере уже полвека назад М. Маклюэн, А. С. Робертсон, Аж. Фридман и некоторые другие исследователи (Маклюэн, 2003; Robertson, 1992; Фридман, 2011). Они подчеркнули, что «the Medium is the Message» - т. е. средство сообщения есть само сообщение. Тезис о том, что средство передачи информации оказывает принципиальное влияние не только на ее содержание, но и на содержание всей социокультурной реальности, в таких ее основополагающих категориях, как пространство, время, причинность событий, не требует дополнительного подтверждения.

Однако сама установка технологического детерминизма, согласно которой смена средств коммуникации является основополагающим фактором смены исторических 
эпох, требует комментариев. В обозначенных концепциях акцентируется, что современные әлектронные способы передачи информации гармонизируют человеческие отношения, позволяя преодолеть отчуждение между людьми, в отличие от прежних, локализующих пространство и время и усиливающих непричастность индивидов к решению социальных проблем. Сегодня трудно не согласиться с тезисом о влиянии современных коммуникаций на общество - и прежде всего сетевых технологий, которые М. Маклюэн совсем не имел в виду хотя бы в силу их более позднего вхождения в повсеместно распространенные социальные практики.

Сегодня очевидно, что современные информационные технологии выступают не только как основание для развития новых электронных форм существования экономик, банковских систем, правительств, но и как среда, в которой преимущественно разворачивается социальная коммуникация, где индивид может открыть и проявить свои способности, оценить их и осуществить процедуры идентификации. И не столь важно, что ощущение причастности к социальной реальности оказывается иллюзорным, а полноценное общение уступает место его суррогатному заменителю - такие формы коммуникации социально легитимированы, более того, они являются социально престижными.

В информатизированном обществе носители текстов соответствуют доминирующим способам фиксации и передачи информации, которые отражают тип социальности, уровень исторического развития, особенности культурно-ценностного содержания, ему присущие. Конечно, сложно говорить об оптимальности этих способов передачи информации, но они рождены техническим развитием и соответствуют ожиданиям общества, основным особенностям его развития. Содержание доминирующих в рамках данного общества коммуникационных систем обусловлено как уровнем развития науки и технологий, как особенностями производственной деятельности, так и спецификой социальных отношений, особенностями культуры, содержанием исторического опыта.

Формирование постиндустриальных и «информациональных» (по М. Кастельсу) отношений в современных обществах, в том числе в России, накладывается на не изжившие себя элементы индустриальной экономики и функционирующие до настоящего времени социальные принципы развития общества доиндустриального - особенно в тех странах, где активны процессы трудовой и политической миграции. Однако высокий уровень технологического развития и доминирующие мобильные и сетевые средства сообщения и способы передачи могут парадоксальным образом сочетаться с доиндустриальным типом социальных связей - бедуин в пустыне с мобильным телефоном сегодня не представляется парадоксом.

Означает ли такой скачок в использовании современных технологий отмирание и дезактуализацию присущего предыдущему обществу письменного способа фиксации информации? Является ли цифровой способ закрепления информации более оптимальным не только с точки зрения скорости и чистоты способов ее передачи, но и с точки зрения тех возможностей, которые связаны с ретрансляцией, дешифровкой и восприятием текстов? И уйдет ли из социального пространства как технологически неэффективный письменный способ трансляции информации? Требует ли этого логика цивилизационного развития, все время порождающая более эффективные коммуникационные и информационные системы?

Аумается, полная замена письменного способа фиксации информации цифровым - по крайней мере, в обозримой исторической перспективе - представляется 
невозможной, в первую очередь это касается не технических или научных текстов, а художественных. И не потому, что бумажные носители более надежны в плане случайного или намеренного уничтожения зафиксированной на них информации, а в плане невозможности передачи многих свойств текста посредством его перевода в цифровой формат. Конечно, сам текст при этом может сохранять все свои особенности - линейность, саму форму фиксации и расположения - как, к примеру, это присуще әлектронной книге, но смена носителя изменяет способ функционирования текста.

Пример әлектронной книги не является характерным для того, чтобы говорить о принципиальных изменениях существования литературы в информационном пространстве. Здесь в первую очередь требует осмысления такая новая форма функционирования литературного текста, как сетевая литература. Она сегодня включает такие чисто сетевые феномены, как сетевые библиотеки (одна из первых появившихся в Рунете - библиотека Янко Слава); литературные сайты, форумы, чаты, позволяющие осуществлять не только социальную коммуникацию, но и обмениваться ее участникам достаточно объемными текстовыми фрагментами; литературные сетевые журналы (первые из них, появившиеся в 2000-х годах: «Иягушатник», «Русский переплет», «Сетевая словесность»); литературные сетевые игры (одна из первых интерактивных игр в Рунете - «Буриме» - привела к проявлению таких форм, как «Сонетник», «Пекарня лимериков», «Ренгуру», «Сад расходящихся хокку», первоначально - с 1997 г. существующая в составе Журнала.Ру, далее - на литературном портале «Сетевая Словесность; Сетевой журнал»); литературные сетевые проекты, такие как «РОМАН» Романа Иейбова, предназначенный, по словам автора, «не для того, чтобы его читали, а для того, чтобы его писали»; различные литературные сетевые объединения; проекты наподобие FanFiction, где литературные произведения создаются на основе произведений киноискусства (кинофильмов, аниме, телесериалов, комиксов) и компьютерных игр, а также Original, где авторы создают собственный сюжет с собственными героями, но подчиняющийся общим закономерностям FanFiction (Бычкова, 2015: Электронный ресурс).

Одна из оригинальных форм сетевой литературы - программы для написания стихов на русском языке. Таким, например, является проект Сергея Тетерина «Кибер-Пушкин 1.0 БЕТА». Компьютер, названный «Кибер-Пушкиным» и показанный на выставке в 2015 г. в Электромузее (г. Москва), способен генерировать поэтические тексты на основе загруженных в его базу данных лучших поэтических творений Есенина, Мандельштама, Вертинского. Аействительно, тексты компьютера обладают определенным характером и оригинальностью, напоминающей словесные опыты начала XX в.:

«Гаснут кромкой фонари / Раскудахталась позёмка / Жёхлый вальс листок любви / Распласталась грёз катомка» («Кибер-Пушкин ... : Электронный ресурс). По словам автора проекта, «перемены неизбежны: искусство поэзии станут преподавать в рамках “гуманитарного программирования”, а стихи для любимых будут не писать, а выбирать, как цветы в магазине» (там же). «И тогда нынешним поэтам придется превзойти себя и пойти на революционные творческие инновации, чтобы подтвердить “высоту духа" и сохранить за собой «ауру духовного превосходства» (там же).

Аля того чтобы отразить разнообразие литературного творчества в Сети, исследователь массовой культуры Аж. Кавелти ввел понятие «литературная формула», означающее «тип сюжета» или «фабульный сюжет». В книге «Приключение, тайна и лю- 
бовная история: формульные повествования как искусство и популярная культура» Кавелти дает определение понятию «литературная формула» - это «способы, с помощью которых конкретные культурные темы и стереотипы воплощаются в более универсальных повествовательных архетипах» (Кавелти, 1996: 33). К таковым относятся не только крупные формы, но и такие нарративные формулы, использование которых способствует быстрому усвоению содержания, как «Ахиллес быстроногий», «рыжие вспыльчивые ирландцы», «әксцентричные детективы с недюжинными аналитическими способностями».

Названия новых жанров сетевой литературы, как правило, представляют собой транскрипции англоязычных названий. Среди них исследователи выделяют, по преимуществу, те, которые основаны на таких лейтмотивах, как насилие, страх, сексуальные отношения: Ангст (от англ. angst - страх, беспокойство, тоска, депрессия); БАСМ (BDSM - bondage, domination / discipline, sado-masocbism); Ваниль - жанр сетевого текста, в котором описываются сексуальные отношения без БАСМ; Гапфиллер (англ. gap - промежуток, filler - наполнитель); Грейпфрут; Аарк/Ааркфик; Аесфик; AА (DD, англ. domestic discipline); Арама; Занавесочная история (англ. curtain story); Кроссовер (англ. crossover - перекресток); Кинк (в значении «жанр» от англ. kink - странность, ненормальность, отклонение); Аимон; Пародия; ПВП (РWP, англ. porn without plot - порнография без сюжета); ПОВ (POV, англ. point of view точка зрения); Ретеллинг (англ. retelling - пересказ); Романтика; Смарм (англ. smarm - лесть); Смат (англ. smut - непристойность); Сонгфик (англ. song-fic); Филк; Флафф; Хоррор (англ. borror - ужас, страх); Хорт-комфорт (кнут и пряник); Экшен/экшн; Юмор (Бурцева, 2014: Электронный ресурс).

Однако странным образом из этого перечня выпадают те сюжетные формы, в которых представлены любовь (а не секс), дружба, самопожертвование, достижение целей, героизм и многое из того, что наполняет Большую литературу. И это позволяет предположить, что сетевая литература - в силу своей сжатости в пространстве (сетевой текст, как правило, не может состоять из 1000 страниц) и во времени (чтение такого текста не может, как правило, соответствовать прочтению объемного художественного материала) - апеллирует преимущественно к тем ситуациям, которые выступают как наиболее сильные раздражители. Сказанное вовсе не является правилом примером тонких сетевых интеллектуальных литературных игр выступают перечисленные выше проекты. Кроме того, необходимо помнить, что сетевая литература использует такие свойства Сети, как нелинейность и опора на гиперссылки, благодаря которым образуется гипертекст; интерактивность, позволяющая вторгаться в текст, дописывать его или, по крайней мере, разгадывать, что позволяет говорить о трансформации читателя в Образцового читателя; мультимедийность, предполагающая трансформации текста посредством включения в литературное произведение звуковых файлов, анимированных изображений и т. п.

Кроме того, весьма важно выявить ту специфику, которой обладают литературные тексты, существующие в сетевом пространстве, а также те функции, которые выполняет подобная литература в современном мире.

\section{ТЕКСТЫ СЕТЕВОЙ АИТЕРАТУРЫ: \\ ОТ АИНЕЙНОСТИ - К РИЗОМАТИЧНОСТИ}

Первая часть задачи, связанной с анализом сетевой литературы, достаточно элементарна - все тексты, выложенные в Сеть, можно разделить на две группы. Первые 
созданы по законам линейного текста и могут быть расположены на определенных ресурсах - библиотеках, журналах и т. А. и т. п. Их нахождение в сетевых хранилищах никак не влияет на их специфику. Это привычные для нас тексты, опирающиеся на принципы связности, последовательности изложения, линейности, завершенности и замкнутости текста на себя. Конечно, многие литературные опыты модернистской литературы намеренно нарушают эти принципы - возможно, все, кроме одного главного - традиционный, не сетевой, текст замкнут на себя, все связи данного текста с другими происходят только в воспринимающем сознании, и этот текст не подлежит коррекции.

Вторая группа текстов создана совершенно по другим законам. Эти законы определяются особенностями строения самой Сети, главными признаками которой выступают создание нового пространства - киберпространства - и нового времени - вневременного, существующего в режиме реального времени (on line), т. е. времени настоящего. И это киберпространство существует по своим собственным законам «опирается на систему связей-ссылок между текстами на основе универсального гипертекстового языка (HTML) и стандартного формата адресов (URL)» (Можейко M., Можейко В., 2002: 316-317). Подобная структура сетевых текстов обусловлена структурой Интернета, «основанного не на иерархичном, а на сетевом принципе организации. В такой системе все узлы находятся в соотношениях не соподчинения второстепенного - главному, периферии - центру, а в соотношениях рядоположенности. Сеть наглядно демонстрирует, что кибернетический принцип упорядочивания информации, основанный на команде, исходящей из центра системы, сменяется более проАуктивным принципом - синергетическим, где упорядочивание происходит как самоорганизация» (Костина, 2016: 73).

Эти принципы интерактивности и интертекстуальности разрушают саму систему литературы до-сетевой (классической, существующей на бумажных носителях, традиционной, линейной) и ее основные принципы - замкнутости текста, единственным создателем которого является Автор, и невозможности трансформаций текста, допускающих его незавершенность.

Здесь необходимо сделать ремарку относительно специфичности текстов постмодернистской литературы. Несмотря на ее вполне традиционную - книжную - форму, где носителем текста является бумага, - она допускает и более того, предполагает, сведение функций Автора до значения Писателя, и даже до предельной формы такой трансформации - Смерти Автора, она настроена на диалог с другими текстами и стремление в пределе к гипертексту. Она может преодолевать принципы линейности, логичности, последовательности и тем более классического детерминизма. Но все эти трансформации авторского текста могут быть осуществлены только в воспринимающем сознании. Именно эта значимость индивида, воспринимающего текст, позволяет его рассматривать в качестве Образцового Читателя, а его сознание - как «словарь», «энциклопедию» (У. Эко), «космическую библиотеку» (В. Аейч) - т. е. как мегатекст, не имеющий границ. Эти понятия, рожденные постмодернизмом, подчеркивают только одно - настроенность на взаимодействие с читателем, который обладает той же совокупностью знаний (в пределе), что и писатель. Однако никогда эти тексты, до тех пор, пока они намеренно не выложены в Сеть для их трансформации и работы с ними, не будут сетевыми текстами, а их сходство с сетевой литературой обусловлено появлением и развитием Интернета, как раз опирающегося на систему гиперссылок. 
Этот принцип, неизбежно становящийся принципом постмодернистской литературы, выступает как системообразующее качество самой культуры постмодерна. Ее образом, по словам Ж. Аелеза и Ф. Гваттари (Аелез, Гватари, 1990, 1996), становится ризома - система, по своей структуре и особенностям функционирования напоминающая корневище, не имеющее ярко выраженных центра и периферии, и не подчиняющаяся законам культуры модерна, образ которой авторы определяют как дерево. Аерево - в отличие от ризомы - имеет ствол (главное) и ветви (второстепенное), верх (доминирующее) и низ (подчиненное), правое (верное) и левое (неверное), что позволяет говорить о наличии центра и периферии. Культура же постмодерна развивается вне бинарных оппозиций, не приемлет принципов главного второстепенного, верного - неверного, центра - периферии, господства - подчинения, позитивного - негативного, своего - чужого, высокого - низкого, единства - множества, массового - элитарного, подлинника — копии, уникального тиражированного и т. п. Основными свойствами культуры постмодерна становятся тотальная децентрализация, волатильность, взаимопроникновение центра и периферии, отсутствие оппозиции между господствующим и подчиненным, между макро- и микросоциальными группами, между глубиной и поверхностью социального тела, между тем, что культура охватывает, и тем, откуда она исходит (Фуко, 1996: 192-194).

Теперь системность сменяется антииерархичностью, прямая последовательность значений - нелинейной логикой, стремление видеть во всем взаимообусловленность и взаимоподчиненность элементов - семантическим и ценностным плюрализмом.

Утверждение информационного общества, доминирование мультимедиа, распространение виртуализированного сознания - все эти особенности прекрасно схватывались при помощи постмодернистских подходов, где понятия симулякра ( «пустого» знака, ничего не означающего) и симуляционной реальности, введенные Ж. Бодрийяром, становятся точными аппаратами описания среды мультимедиа. Фактически Бодрийяр отразил парадокс развития «общества знания», доказав, что увеличение количества информации, изоляция от которой практически невозможна, приводит не к информированности, а значит, накоплению знания человека о мире, а к поверхностности - сначала восприятия, затем - мышления. Человек утрачивает способность оперировать завершенными текстами и логическими конструкциями, а формирует реальность из фрагментов впечатлений и обрывков текстов.

Способность текстов, благодаря системе взаимоотсылок, существовать в виде совокупного текста, образуемого различными версиями, вариантами текстов при отсутствии первообразца, характерного для письменной культуры, образует гипертекст. Подобными образцами интер- и гипертекстуальности наполнены сайты Интернета, где тематические группы текстов образуют своеобразные гипертекстовые конструкции, а включение разных текстов в один - интертекстуальные формы ${ }^{1}$. Таким образом, постмодернистская интертекстуальность является отражением реально функционирующих текстов.

Если говорить о принципах образования сетевых текстов, развивающихся в режиме on-line, они состоят в том, что все сообщения объединяются в треды (от англ. thread - «нить»). Причем все входящие сообщения группируются не по времени их поступления, а по тематике. При этом исходные сообщения вместе со всеми репликами-реакциями на них образуют тематические «ветви»- ответы на ответы, развивающиеся вокруг определенных проблем. Подобная структура напоминает дерево, ветви 
которого и образуют треды. Ярким воплощением такой ризоматической структуры стало одно из первых произведений сетевой литературы - феноменальный проект «РОМАН» Романа Аейбова, сегодня, к сожалению, завершенный.

Суть проекта можно определить при помощи еще одного понятия, раскрывающего сущность сетевого творчества, - понятия интерактивности, т. е. вовлеченности в процесс творения чего-либо (в равной степени - болтовни в чате, создании совместного перевода или романа). При этом любой мог продолжать начало «РОМАНА», которое было выложено в Сети, с любого момента текста, в результате чего текст, имеющий древовидную структуру, стремительно разросся, приобретая черты незавершенности, длящейся процессуальности. При этом автор с самого начала полагал, что завершения «РОМАН» не получит никогда, так как это будет противоречить принципам интерактивности. Автор допускал прекращение проекта только вследствие волевого решения, которое мог бы принять редактор, но это будет противоречить идее. А она состоит в главенстве процесса над результатом, где сам «РОМАН» вообще нельзя рассматривать как текст, так как он не имеет границ, а его структурированность все время меняется. Сам Р. Аейбов так вспоминает о начале проекта:

«Его начало состоялось 10.10.95. Идея была моя. Возникла она так - играя в манинское буриме, я задумался над тем, как построить нечто аналогичное для нарратива (повествовательно-сюжетного дискурса). Одновременно я пытался писать небольшие гипертекстики (не читая тогда англоязычных аналогов). Первый, помнится, назывался «Как Горный прочитал гипертекст» (ссылки были и внутренние, и внешние). Потом уж в Стокгольме я писал нечто научное об исторических нарративах и их многовариантности. Все это и соединилось в идее РОМАНА.

Первыми читателями были $\Lambda$. Аелицин (которому я по гроб благодарен за бескорыстное сочувствие и самозабвенное отзеркаливание и техобслуживание), А. Бальзак, Е. Горный (однофамилец героя упомянутого рассказика) и Михаил Ашаров (раз уж Куб использует этот псевдоним, так и буду его называть). Первых двоих проняло, вторых - решительно нет. Исходный текст датирован 1987 годом, я его сам сочинил и искусственно разбил на субтексты. Первые читатели решили, что это - чистой воды автобиографизм и лирика. На самом деле - абсолютная фикция и подражание Харитонову (не Марку)... Сколько авторов (у РОМАНА), точно сказать не могу (некоторые меняли псевдонимы). Около 20, наверное. Скорость роста - переменная величина. После первого романтического периода (месяца три он длился), когда несколько человек писали каждый день и двигали наметившиеся в первые недели сюжетные линии более или менее согласованно (большая часть написана именно тогда, ровно $2 / 3$ ), наступило время отступлений в разные стороны, пересыхания сюжетных русл и авторов-одиночек. Попишет-попишет, а потом охладеет и бросит... Если представить, что РОМАН вдруг закончился, все разучились писать или у всех вдруг отвалились пальцы, а только у меня бы остались, тогда бы я наконец и принялся это все изучать. Статью бы сочинил о нарративе. Впрочем, если б я остался единственным на Земле человеком с пальцами, это сильно изменило бы мои привычки...» (Книга для всех .... : Электронный ресурс).

Еще одним интерактивным проектом в Сети, в котором принимал участие Р. Аейбов (при участии Амитрия Манина и дизайнера Михаила Аейпунского), является «Сад расходящихся хокку» - одна из первых интерактивных литературных игр в Рунете, существующая с 27 сентября 1997 г. (первоначально в составе «Журнала.Ру», далее на литературном портале «Сетевая Словесность»). Согласно материалам из «Ви- 
кипедии», участникам игры предлагается дописать хокку по первой или последней строке, случайно выбранной из массива уже существующих текстов. Используются канонические правила хокку: 3 строки, количество слогов $5+7+5$. В результате связи всех текстов по строкам возникает многомерный лабиринт, состоящий из бесконечно ветвящихся и пересекающихся цепочек, или тропинок Сада, по которым читатель может путешествовать, переходя по ссылкам. Иными словами, в проекте «Сад расходящихся хокку» образ, строка или слово становится посылом для создания нового произведения².

\section{СЕТЕВАЯ АИТЕРАТУРА:}

\section{СОЦИААЬНЫЙ ФУНКЦИОНАА КАК ВЕАУЩИЙ}

Теперь, когда мы выявили специфику сетевых литературных текстов, обратимся к вопросу о тех функциях, которые выполняет сетевая литература в современном мире. Самая главная особенность, которой обладает сетевая литература, связана, как это ни странно, не с ее содержанием - здесь она, безусловно, уступает классической не-сетевой литературе. Главное качество сетевой литературы - это качество социальности. Конечно, сказанное не означает отсутствие такового свойства у традиционной литературы - и она выполняла целую совокупность социальных функций, формируя картину мира, раскрывая ценности той или иной культуры, определяя доминанты общественных отношений и их соотнесенность со структурой общества. Однако эта литература осуществляла связь между людьми через посредника - Автора, который и задавал размерность, направленность и матрицы этой коммуникации. Подобная письменная коммуникация, кодифицированная в знаках алфавита и пришедшая на смену оро-акустическим формам общения, как убедительно показал еще в 1960-е годы М. Маклюэн, «локализовывала пространство и время, усиливала отчуждение, ликвидируя сопричастность отдельных индивидов к социальным процессам» (McLuhan, 1967: 13). Конечно, мы осознаем, что данный тезис позволил Маклюэну выступить апологетом новой аудиовизуальной эпохи, восстановившей «нарушенный сенсорный баланс» и позволившей человеку получать информацию более эффективно, полно, быстро и выступать благодаря этому жителем «глобальной деревни». И несмотря на то что свою последнюю работу М. Маклюэн издал в 1977 г. (McLuhan, Hutchon, McLuhan, 1977), в то время, когда Интернет был уже открыт для пользователей, новую сетевую культуру исследователь не проанализировал в той же мере, как культуру телевидения.

Но именно сетевая коммуникация выступает как полноценный заменитель реальному, живому общению, осуществляющемуся непосредственно. Аа, конечно, оно несет целый ряд издержек, среди которых - виртуализация бытия. Но такая коммуникация дает и другое - возможность быть участником социальных событий посредством их активного обсуждения. В литературе же это открывает новую эпоху - эпоху сотворчества, возможности участвовать в литературных проектах на правах не потребителя (Читателя), а творца (Автора). Примером такой литературы может выступить проект Стихи.Рy (http://www.stihi.ru/) - крупнейший российский литературный портал, работающий под эгидой Российского союза писателей, опубликовавший на 11 июня 2017 г. 37868333 произведения - стихов самых разных, и в первую очередь неизвестных, непрофессиональных, авторов.

Наблюдение за развитием этого проекта в течение по крайней мере восьми лет позволило автору данной статьи сделать ряд выводов о сетевой литературе в целом. 
И главный из них связан с социальной значимостью проекта, в котором художественность текста не всегда выявлена, но всегда присутствует реализованная возможность высказывания, осуществленного в художественной форме. Аа, конечно, не все произведения этого портала литературно совершенны. Весьма малое количество текстов можно рассматривать как те, что создают пространство идеального как «особой «сверхприродной» объективной действительности» (Ильенков, 1979: 140), той реальности, в которой реализуются потенции самих вещей, «которые и есть собственные его потенции» (Свасьян, 1987: 132-133). Отнюдь не во всех произведениях данного портала присутствует созданная самим автором особая идеальная реальность, не опирающаяся на данный человеку в его эмпирическом бытии опыт.

Это пространство идеального не дано обыденному сознанию, однако человек всегда стремится к полноте информации и полноте отражения мира, но в данном случае это зачастую осуществляется во вторичных формах, в облегченных образах, в интеллектуальной поверхностности, в стремлении осмыслить наиболее яркие собственные переживания, среди которых доминируют любовь и разлука. О подобном опыте в аспекте размышления о книгах для элиты и массы пишет В. Г. Федотова, делая вывод о том, что отказ от конструирования особой дитературной реальности рождает псевдоклассику, а сама литература «начинает заставлять видеть мир в пределах определенным образом организованной литературной практики, которая воспроизводит одну и ту же форму видения реальности...». «Хуже того, - подчеркивает В. Г. Федотова, - литературному опыту начинает довлеть одна-единственная реальность, которая в своем дальнем пределе совпадает с господствующей литературной формой» (Федотова, 2000: 227).

И все же, несмотря на то что стихи, размещенные на данном портале, не всегда отвечают обозначенным выше требованиям, право на активное развитие и всяческое поощрение они, безусловно, имеют, и прежде всего потому, что в мегаполисах, где люди крайне отчуждены друг от друга, подобные проекты включают в свое пространство все большее количество участников, становясь не только аналогом дичного общения, но и полноценным его заменителем. И не столь принципиально, каковы те социальные группы, которые разворачивают свою активность именно в Сети, важно, что их чрезвычайно много.

Эти группы различны по численности (количество участников проекта Стихи.ру может доходить до нескольких тысяч, а интересующихся техникой смычка в Италии в XVIII в. могут быть единицы); входящие в эти сообщества преследуют разные цели (от преодоления одиночества до простого структурирования времени); они различны по степени включенности в сетевую жизнь (для одних - это пара рекреационных часов, Аля других - ежедневное многочасовое общение, в процессе которого осуществляется вся частная жизнь, описываемая в выкладываемых в Сеть произведениях. Самое главное, что таких сообществ становится все больше и больше. Это связано, конечно, и с тем, что свободное время, особенно у людей, включенных в «информационную деятельность», не структурировано, как не определено и рабочее пространство, зачастую представляемое не офисом, а домашним рабочим столом. Все это делает естественным для таких людей постоянное нахождение в Сети и участие в жизни «мировой паутины». Образуемые в Сети сообщества вырабатывают новые нормы общения, рождают новые смыслы культуры, формируют новые ценностные системы, собственную идеологию, свои приоритеты, образцы поведения, идеальные качества личности, стратегии жизнедеятельности. 
И многие из этих форм закрепляются, становятся привычными - сначала в рамках одного сообщества, затем - если эти установки соотносятся с представлениями иных групп - многих. Все это свидетельствует о существенном влиянии сетевой культуры на культуру в целом, о том, что сетевые формы коммуникации соответствуют потребностям и ожиданиям людей и отражают те доминантные смыслы культуры, которые, складываясь в сетевых сообществах, распространяются в обществе в целом.

\section{АДАПТАЦИОННЫЙ ПОТЕНЦИАИ СОВРЕМЕННОГО ЯЗЫКА: \\ САЕНГ КАК ЗАЩИТА ОТ «ШОКА БУАУЩЕГО »}

Все функциональные особенности, присущие сетевой литературе, атрибутивны для языка, особенно современного, в целом. Он стремительно изменяется - и не только вследствие изменения материального мира и появления новых форм социальности, требующих означивания, а вследствие появления новых видов угроз, защиту от которых общество ищет, в том числе, в языке.

Одной из глобальных проблем современности - наряду с нищетой, неграмотностью, экологическими проблемами - сегодня многие ученые и общественные деятели признают терроризм. Самым страшным терактом XX в. остались в памяти всех людей события в США 11 сентября 2001 г. Вопреки опасениям среди американских подростков это событие не привело к вспышке этнонационализма, однако существенно преобразило их сленг. В Интернете на сайте Inopressa.ru. была выложена статья из британской газеты The Guardian «Американские подростки сменили сленг после терактов 11 сентября», содержащая описание многих слов и выражений американских школьников. «Самое популярное обозначение тех, кто отстал от жизни - “десятое сентября”. Немодно одетая девочка рискует услышать вопрос - “Ты чадра?” А требование учителей остаться после уроков и прочие дисциплинарные взыскания ученики называют “джихадом”. "Если ты ведешь себя странно, тебя могут назвать талибом или спросить, не заболел ли ты сибирской язвой”, - сообщила газете американская школьница палестинского происхождения Найва Авад» (Американские подростки ..., 2002: Электронный ресурс).

По мнению The Guardian, многие мусульманские и арабские дети защищаются с помощью шуток. Они находят возможности извлечь пользу из опыта пребывания в роли отрицательного персонажа. «11 сентября оказалось очень сильным потрясением, поэтому нет ничего дурного в том, чтобы немного пошутить», — говорят они. Новый террористический сленг был выявлен в результате исследований, проведенных Центром изучения насилия Ажорджтаунского университета. Алан Иипман и его студенты побеседовали с подростками, пытаясь выяснить, какое влияния на них оказали события 11 сентября. «Вот некоторые другие примеры нового сленга: о мальчиках говорят “симпатичный, как пожарник”; о раздражительном учителе - “террорист”; неприбранную комнату называют "ground zero", блюдо с большим количеством специй - “оружейным”» (там же).

Не менее мощным фактором, влияющим на развитие языка, является изменение технологий, которые обусловливают изменение и социальных практик. В настоящее время на стиль речи, сформировавшийся по преимуществу у молодежи, наибольшее влияние оказывает повсеместное распространение мобильных телефонов, SMS и электронной почты, что ведет к распространению «телеграфного стиля». Еще в 2003 г. в Интернете появилось сообщение о том, что британская школьница написала сочинение в форме SMS-сообщения: «Школьница уточнила, что она нашла этот способ 
“более легким, чем стандартный английский язык” (Британская школьница ..., 2003: Электронный ресурс). Но учителя заявили, что в результате написанного в виде стенографии текста сложно проверить грамотность ученицы. Преподаватель, пожелавшая остаться неназванной, призналась, что просто не могла поверить тому, что увидела. «Страница была исписана неразборчивыми иероглифами, многие из которых я просто не могла перевести», - возмутилась учительница. Сочинение подростка начиналось так: «My smmr hols wr CWOT. B4, we usd 2go2 NY 2C my bro, his GF \& thr 3 :kds FTF. ILNY, it's a gr8 plc». Перевод на английский должен выглядеть так: «My summer holidays were a complete waste of time. Before, we used to go to New York to see my brother, his girlfriend and their three screaming kids face to face. I love New York, it's a great place». По-русски это звучит так: «Мои летние каникулы были сплошной тратой времени. Раньше мы ездили в Нью-Йорк навестить моего брата, его подругу и их трех орущих детей. Я люблю Нью-Йорк, это великолепное место» (там же).

Этот прецедент вызвал целый шквал эмоций со стороны общественности и специалистов. По мнению Ажудит Гиллеспи, преподавателя из Шотландского родительского совета, эта тенденция достаточно опасна, и снижение в стандартах грамматики и письменной речи обусловлено повсеместным увлечением молодежи SMS-сообщениями. По ее убеждению, необходимо принять серьезные меры для аннулирования самой формы SMS как варианта письменного языка, так как это влияет на содержание самой культурной традиции в Англии, будущее которой вызывает серьезную обеспокоенность.

В отечественной культуре подобным воплощением письменной фиксации устной речи стал язык русскоязычной сетевой субкультуры, которая оформилась приблизительно в самом конце 1990-х годов и сегодня уже утратила социальную актуальность. Сленг этой субкультуры, получивший самоназвание жаргона «падонков», стал позже основой так называемого албанского языка. Согласно материалам из Википедии, а также Рекламного плаката журнала «Русский Newsweek», движение это зародилось на одном из сетевых ресурсов (Албанский клан, Электронный ресурс), затем в нем произошел раскол, и основным сайтом стал Udaff.com, созданный Удавом - видным деятелем движения. В идеологическом отношении можно отметить определенную близость этого феномена к контркультуре, протестной панк-культуре и рассматривать как разновидность отечественного трэша. На этом специфическом языке представители русскоязычной сетевой субкультуры писали рассказы, рецензии на книги, фильмы и музыку, статьи об актуальных событиях, устраивали массовые акции в гостевых книгах известных персон и т. п. Буквально через несколько лет это движение устоялось и стало частью культурного мейнстрима. Сама русскоязычная сетевая субкультура сложилась приблизительно в 2000 г. или даже на два-три года ранее (там же).

Возникновение же термина «албанский» язык (или «олбанскей») связано с Живым Журналом, где рунетовское общество активно приняло язык «падонков». История возникновения «албанского» языка, как следует из Википедии, такова: «пользователь оnератор из России опубликовал фотографии, снабдив их русскими комментариями. Пользователь scottishtiger (американец из Такомы, штат Вашингтон, шотландского происхождения) задал вопрос, на каком языке написаны комментарии, и получил ответ от русского maxxximus, что это, дескать, албанский. На следующий день scottishtiger в ответ на вопрос “А почему Вы думаете, что комментарии были написаны для Bac?” написал: “Потому что это американский сайт, а не албанский. Кроме того, быть 
американцем означает, что остальной мир должен обслуживать меня". На это оneратор организовал флешмоб "Уроки албанского языка", после которого записи блога scottishtiger были завалены комментариями на русском языке, обобщением которых стала фраза "Учи албанский!", после чего это выражение стало нарицательным. С тех пор в среде “падонков” фраза “Аффтар, учи албанский” означает указание на ограниченность человека, которому она адресуется» («Албанский язык»... : Электронный ресурс).

В основе творческого метода представителей движения - провокация и эпатаж, использование обсценной лексики, преднамеренное искажение языка при помощи орфографических и семантических ошибок. В Сети даже появился краткий и литературно-ироничный «русско-албанский» словарь. Характерно, что на «албанский» язык в Сети вскоре появилась пародия - так называемый старословянской язык (ЦСЯ). Язык носит в значительной степени подражательный и пародийный характер, хотя есть версия, что к созданию «старословянского» языка причастны люди, знающие церковнославянский язык на самом деле. Наиболее яркие выражения ЦСЯ по преимуществу являются «переводом» выражений на «олбанском» наречии ( Писарь ... : Электронный ресурс). Уже к середине десятых годов движение коммерциализировалось, сам язык устоялся, а большинство текстов стало писаться по шаблону. К настоящему времени движение потеряло актуальность, а неграмотность на форумах вызывает раздражение и воспринимается негативно - как неграмотность и необразованность.

Содержание русскоязычной сетевой культуры составляют не только грамматически искаженные слова, но также неологизмы, а также транслитерации, совмещения (или замены части) слов английского и русского языка. Это развивающийся процесс, и оценить его адекватно достаточно сложно - по-видимому, в языке останется лишь то, что находит соответствие в матрицах самой культуры. В то же время эти тенденции вызывают достаточное опасение - хотя бы в связи с тем, что препятствуют формированию логичного мышления под влиянием письменного текста.

Этот тип текста, который сегодня формируется в Интернете, исследователи обозначают как «устно-письменный текст», как «спонтанную письменную речь» (Зализняк, Микаэлян: Электронный ресурс), письменную разговорную речь, своеобразную смесь письменного литературного и устного разговорного языка (Буторина, 1999), который попадает в Сеть в письменной форме, но при этом воспринимается как передаваемый «из уст в уста» (Радченко, 2006: 307) и является письменностью особого рода.

Некоторые исследователи говорят о формировании качественно нового функционального «подстиля», наиболее ярко проявляющегося в чатах, где стиль разговорного жанра проявляет себя наиболее ярко. Хотя, конечно, необходимость обмена репликами в письменной форме накладывает на этот стиль свой отпечаток. Можно этот язык рассматривать и как своеобразный языковый стиль, подобный сленгу или жаргону. Стремительность распространения подобного языкового стиля, как предполагают исследователи, в скором времени неизбежно поставит вопрос о необходимости создания кодекса речевого поведения в Сети. Обсуждения «лингво-этического кодекса пользователей Интернета», связанного с применением грамматических и стилистических правил, регулярно происходят на форуме «Русский язык в Интернете» (http://www.trworkshop.net/forum/viewtopic.php? $\mathrm{f}=55 \& \mathrm{t}=60362$ ). Необходимость подобных обсуждений связана с тем, что значительное число самих пользователей Сети 
является людьми, прекрасно образованными, понимающими, что культурный уровень участника коммуникации - а следовательно, и его социальная значимость - оценивается по степени его речевой грамотности, и искажение языка вызывает у них значительные опасения.

Однако неверным было бы суждение о языке интернет-сообществ только по негативным примерам, связанным с намеренным или случайным (безграмотным) искажением русского языка. Многие сообщества - в частности, участники фанфиков (движения так называемого «народного перевода») - люди, прекрасно владеющие языковой культурой, профессионально занимающиеся языком. Соответственно, Интернет содержит и значительное число иных примеров - афоризмов и высказываний, составленных как философские максимы. И не важно, что они напоминают изречения выдающихся людей - писателей, ученых, философов, важно, что они создаются, что они привлекают внимание и обсуждаются.

\section{ЗАКАЮЧЕНИЕ}

Итак, язык является отражением культуры - по содержанию словаря можно точно судить о глубине культурной традиции, о степени ее развития. Недаром Й. Гердер называл его «вместилищем культуры». Язык является достаточно инертным феноменом, его модификация происходит достаточно медленно, и это понятно - быстрое изменение словарного состава языка, способов построения предложений и многого Аругого привело бы к тому, что язык утратил бы свою первоочередную функцию служить способом коммуникации. Однако сегодня, в связи с активизацией межкультурного общения вследствие развития мультимедиа и глобализационных тенденций, национальные языки стремительно изменяются, становясь своеобразной формой социокультурной адаптации. На этот процесс в наибольшей степени влияют три тенденции - глобализационные процессы; развитие технологий, применяемых для передачи вербальных посланий; трансформация социокультурной среды, драматические, как правило, события, заставляющее язык реагировать на эти изменения и отражать их.

\section{ПРИМЕЧАНИЯ}

1 Этот прием отсылок к другим текстам активно используется в сетевом анекдоте, где в едином событийном пространстве присутствуют персонажи из различных культурных текстов: «Нео открывает последнюю дверь, смотрит, а там сам Билл Гейтс сидит. Нео подумал: “И зачем я с этой матрицей боролся? Она бы и сама грохнулась” », «Аетит Нео в позе Супермена и, обращаясь к зрителям, спрашивает: “У вас нет агентов Смитов? Нет? Тогда мы летим к вам!”» (Мрачные анекдоты. Ч. 2: Электронный ресурс); «Матрица. Перезагрузка». «Титаник. Всплытие» (Мрачные анекдоты. Ч. 3: Электронный ресурс). Подобная интертекстуальность прослеживается в изречениях Козьмы Пруткова, которые также становятся предметом словесной игры, к примеру, в «матричной» обработке: «Если хочешь быть Избранным, будь им», «Прозорливая женщина подобна Пифии». Это также подражания «подобиям» Козьмы Пруткова на тему все той же «Матрицы»: «Тринити подобна дорогой машине - всякий любит ее за то, что она состоит при Избранном, но не всякий за то, что она женщина» (Костина, 2009: Электронный ресурс).

2 Это может быть образ следа самолета как последней соломинки, связывающей любящих людей, какое-либо словосочетание (например, «ледяной ливень») или ключевое слово (к примеру, «кукушка»): - Ты улетела / вот и в небе не найти / белой соломины. / - Пустое небо / вот уже не найти и / белой соломинки. / - Ты улетела / последняя соломинка / белеет в небе. / - Аедяной ливень: / только что не кипит / капля на коже./ - Медяной ливень - / ты аб- 
солютно пуста / дорога домой. / - Медяной ливень / над могилами всех / главных конфессий. / - Кукушка в горах. / Запишите меня / в долгожители. / - Кладбище. / Молча сидит на ветке / Кукушка (Книга Авух Су: Электронный ресурс).

\section{СПИСОК АИТЕРАТУРЫ}

«Албанский язык» - как искажение языка [Электронный ресурс] // Vikent.ru. URL: http://vikent.ru/enc/5083/ (дата обращения: 12.01.2016).

«Кибер-Пушкин. 1.0 Бета» [Электронный ресурс] // Кибер-Пушкин. 1.0 Бета. URL: http://www.teterin.ru/pushkin/ (дата обращения: 27.07.15).

«Писарь возжигаше!» Учи старОсловенскОй [Электронный ресурс] // pretty13.beon.ru. URL: http://pretty13.beon.ru/691-223-quot-pisar-vozzhigashe-quot-quot-uchi-staroslove.zhtml (дата обращения: 12.06.2017).

Албанский клан [Электронный ресурс] // Албанский клан. URL: http://albanskey.clan.su/ publ/1-1-0-4 (дата обращения: 12.01.2016).

Американские подростки сменили слэнг после терактов 11 сентября (2002) [Электронный pecypc] // Newsru.com. 21 марта. URL: http:// http://www.newsru.com/world/21mar2002/ childs.html (дата обращения: 12.01.2016).

Британская школьница написала сочинение в форме SMS-сообщения (2003) [Электронный peсурс] // Newsru.com. 3 марта. http://www.newsru.com/world/03mar2003/sleng.html (дата обращения: 12.01.2016).

Бурцева, Е. А. (2014) Жанры сетевой литературы [Электронный ресурс] // Современные проблемы науки и образования. № 5. URL: https://science-education.ru/ru/article/view? id=14665 (дата обращения: 28.05.2017).

Буторина, Е. П. (1999) А поговорить? Интернет как лингвистический феномен // Мир медиа XXI. № 1. C. 56-58.

Бычкова, О. И. (2015) Сетевая литература: вопросы формы и стиля [Электронный ресурс]// Наследие веков. №2. URL: http://heritage-magazine.com/wp-content/uploads/2015/10/2015_2_ Bychkova.pdf (дата обращения: 15.02.2017).

Аелез, Ж., Гватари, Ф. (1990) Капитализм и шизофрения. М. : Анти-Эдип.

Аелез, Ж., Гватари, Ф. (1996) Ризома // Философия эпохи постмодерна : сб. переводов и рефератов / под ред. А. Усмановой. Минск : Красико-принт. С. 6-31.

Зализняк, А., Микаэлян, И. Переписка по электронной почте

как лингвистический объект [Электронный ресурс] // Dialog 2017. URL: http://www.dialog21.ru/digests/dialog2006/materials/html/zalizniak.htm (дата обращения: 12.06.2017).

Ильенков, Э. В. (1979) Проблема идеального // Вопросы философии. №6. С. 128-140.

Кавелти, А. (1996) Приключение, тайна и любовная история: формульные повествования как искусство и популярная культура // Новое литературное обозрение. № 22. С. 33-64.

Книга Авух Су. [Электронный ресурс] // Книга Авух Су. URL: http://hokku.netslova.ru/ hokku_kniga.cgi?7 (дата обращения: 12.06.2017).

Книга для всех и ни для кого [Электронный ресурс] // Классика русской паутины. URL: http://www.kulichki.com/classic/leybov.htm (дата обращения: 12.06.2017).

Костина, А. В. (2009) Молодежная культура и фольклор [Электронный ресурс]// Информационный гуманитарный портал «Знание. Понимание. Умение». № 4. URL: http://www.zpu-journal.ru/e-zpu/2009/4/Kostina_Youth_Culture/ (дата обращения: 12.06.2017).

Костина, А. В. (2016) Интернет-сообщества: что обсуждается в Интернете? От думеров - до фурри. От игнора - до троллинга. М. : УРСС. 176 с.

Маклюэн, Г. М. (2003) Понимание Медиа: Внешние расширения человека : пер. с англ. М. : КАНОН-пресс-Ц; Ж Жуковский : Кучково поле. 462 с.

Можейко, М. А., Можейко, В. А. (2002) Интернет // Всемирная энциклопедия. Философия. XX век / гл. ред. А. А. Грицанов. М. ; Минск ; АСТ ; Харвест. 976 с. С. 316-317.

Мрачные анекдоты. Ч. 2 [Электронный ресурс]// Аожки. NET. URL: http://lozhki.net/anec_ 030903.shtml (дата обращения: 12.06.2017). 


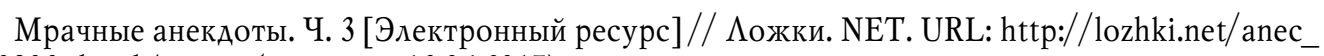
120903.shtml (дата обращения: 12.06.2017).

Радченко, А. А. (2006) Современный кинематографический анекдот в условиях сетевой коммуникации // Первый Всероссийский конгресс фольклористов. Сборник докладов. М. : Государственный республиканский центр русского фольклора. 440 с. С. 307-317.

Рыбаков, Я. (2016) Студенты не смогли отличить консультацию искусственного интеллекта от ассистента профессора [Электронный ресурс]// Life.ru. 10 мая. URL: https://life.ru/t/\%D0\% BD $\% \mathrm{D} 0 \% \mathrm{~B} 0 \% \mathrm{D} 1 \% 83 \% \mathrm{D} 0 \% \mathrm{BA} \% \mathrm{D} 0 \% \mathrm{~B} 0 / 407510 /$ studienty_nie_smoghli_otlichit_konsultatsiiu_isku sstviennogho_intielliekta_ot_assistienta_profiessora (дата обращения: 12.06.2017).

Свасьян, К. А. (1987) Феноменологическое познание. Ереван : ИзА-во АН Армянской АССР. 199 c.

Федотова, В. Г. (2000) Информационное общество и книги для элит и масс // Общество и книга: От Гутенберга до Интернета / общ. ред. А. П. Королевой. М. : Традиция. 279 с. C. 222-234.

Фридман, Аж. (2011) Следующие 10 лет : пер. с англ. М. : Эксмо. 320 с.

Фуко, М. (1996) Воля к истине: по ту сторону знания, власти и сексуальности. Работы разных лет : пер. с фр. М. : Касталь. 448 с.

McLuhan, M. (1967) The Guttenberg Galaxy: The Making of Typographic Man. Toronto.

McLuhan, M., Hutchon, K., McLuhan, E. (1977) City as Classroom: Understanding Language and Media. The Book Society of Canada Limited.

Robertson, R. (1992) Globalization: Social Theory and Global Culture. SAGE. 211 p.

Аата поступления: 15.05.2017 2.

\section{MODERN LANGUAGE: «CULTURE RECEPTACLE» OR A FORM \\ OF SOCIOCULTURAL ADAPTATION?}

A. V. KOSTINA

MOSCOW UNIVERSITY FOR THE HUMANITIES

The article considers the new language phenomena whose emergence is stipulated by the development of scientific and technical, social, economic, and cultural factors. This is network literature and its new forms and genres performing various functions - ranging from language, aesthetic, cognitive, to social and communicative. The author shows that today the concept «literature» means a new phenomenon, primarily connected with a possibility of a free public statement. It is shown that the language instantly reacts to change of the sociocultural environment, including, by means of creating not only a whole system of neologisms, but also essentially new language forms.

The names of new genres of network literature are, as a rule, transcriptions of English names. Because of its briefness in space and time, it appeals mainly to the situations that act as the most intense stimulants. Network literature utilizes such Internet properties as non-linearity and reliance on hyperlinks which generate hypertext; interactivity which makes it possible to penetrate into the text, complete it or at least, decipher it.

The main quality of network literature is its sociality. It is network communication that performs as a fully valid substitute for real live communication happening directly. Social groups on the Web vary in number; their participants pursue different goals; they differ in the extent to which they are involved in network life. Internet culture is noted to have a significant impact on culture in general. Network forms of communication meet people's needs and expectations and reflect the dominant implications of culture which form in Internet communities and then spread throughout society.

Keywords: literature; language; culture; sociocultural situation; network literature; globalization; Internet; information society; Web

\section{REFERENCES}

«Albanskii iazyk» - kak iskazhenie iazyka. Vikent.ru [online] Available at: http://vikent.ru/ enc/5083/ (access date: 12.01.2016). (In Russ.). 
«Kiber-Pushkin. 1.0 Beta». Kiber-Pushkin. 1.0 Beta [online] Available at: http://www.teterin.ru/ pushkin/ (access date: 27.07.15). (In Russ.).

«Pisar' vozzhigashe!» Uchi starOslovenskOi. pretty13.beon.ru [online] Available at: http://pretty13.beon.ru/691-223-quot-pisar-vozzhigashe-quot-quot-uchi-staroslove.zhtml (access date: 12.06.2017). (In Russ.).

Albanskii klan. Albanskii klan [online] Available at: http://albanskey.clan.su/publ/1-1-0-4 (access date: 12.01.2016). (In Russ.).

Amerikanskie podrostki smenili sleng posle teraktov 11 sentiabria (2002). Newsru.com, 21 March [online] Available at: http:// http://www.newsru.com/world/21mar2002/childs.html (access date: 12.01.2016). (In Russ.).

Britanskaia shkol'nitsa napisala sochinenie v forme SMS-soobshcheniia (2003). Newsru.com, 3 March [online] Available at: http://www.newsru.com/world/03mar2003/sleng.html (data obrashcheniia: 12.01.2016). (In Russ.).

Burtseva, E. A. (2014) Zhanry setevoi literatury. Sovremennye problemy nauki i obrazovaniia, № 5 [online] Available at: https://science-education.ru/ru/article/view?id=14665 (access date: 28.05.2017). (In Russ.).

Butorina, E. P. (1999) A pogovorit'? Internet kak lingvisticheskii fenomen. Mir media XXI, no. 1, pp. 56-58. (In Russ.).

Bychkova, O. I. (2015) Setevaia literatura: voprosy formy i stilia. Nasledie vekov, no. 2 [online] Available at: http://heritage-magazine.com/wp-content/uploads/2015/10/2015_2_Bychkova.pdf (access date: 15.02.2017). (In Russ.).

Delez, Zh. and Gvatari, F. (1990) Kapitalizm i shizofreniia. Moscow, Anti-Edip. (In Russ.).

Delez, Zh. and Gvatari, F. (1996) Rizoma. In: Filosofiia epokhi postmoderna : sb. perevodov i referatov / ed. by A. Usmanovoi. Minsk, Krasiko-print. Pp. 6-31. (In Russ.).

Zalizniak, A. and Mikaelian, I. Perepiska po elektronnoi pochte kak lingvisticheskii ob»ekt. Dialog 2017 [online] Available at: http://www.dialog-21.ru/digests/dialog2006/materials/html/zalizniak.htm (access date: 12.06.2017). (In Russ.).

Il'enkov, E. V. (1979) Problema ideal'nogo. Voprosy filosofii, no. 6, pp. 128-140. (In Russ.).

Kavelti, D. (1996) Prikliuchenie, taina i liubovnaia istoriia: formul'nye povestvovaniia kak iskusstvo i populiarnaia kul'tura. Novoe literaturnoe obozrenie, no. 22, pp. 33-64. (In Russ.).

Kniga Dvukh Su. Kniga Dvukh Su [online] Available at: http://hokku.netslova.ru/hokku_ kniga.cgi?7 (access date: 12.06.2017). (In Russ.).

Kniga dlia vsekh i ni dlia kogo. Klassika russkoi pautiny [online] Available at: http://www.kulichki.com/classic/leybov.htm (access date: 12.06.2017). (In Russ.).

Kostina, A. V. (2009) Molodezhnaia kul'tura i fol'klor. Informatsionnyi gumanitarnyi portal «Znanie. Ponimanie. Umenie», no. 4 [online] Available at: http://www.zpu-journal.ru/e-zpu/ 2009/4/Kostina_Youth_Culture/ (access date: 12.06.2017). (In Russ.).

Kostina, A. V. (2015) Internet-soobshchestva: chto obsuzhdaetsia v Internete? Ot dumerov - do furri. Ot ignora - do trollinga. Moscow, URSS. 176 p. (In Russ.).

Makliuen, G. M. (2003) Ponimanie Media: Vneshnie rasshireniia cheloveka : transl. from Engl. Moscow, KANON-press-Ts; Zhukovskii, Kuchkovo pole. 462 p. (In Russ.).

Mozheiko, M. A. and Mozheiko, V. A. (2002) Internet. In: Vsemirnaia entsiklopediia. Filosofiia. XX vek / A. A. Gritsanov (ed.). Moscow, Minsk, AST; Kharvest. 976 p. Pp. 316-317. (In Russ.).

Mrachnye anekdoty. Ch. 2. Lozhki.NET [online] Available at: http://lozhki.net/anec_030903. shtml (access date: 12.06.2017). (In Russ.).

Mrachnye anekdoty. Ch. 3. Lozhki.NET [online] Available at: http://lozhki.net/anec_120903. shtml (access date: 12.06.2017). (In Russ.).

Radchenko, D. A. (2006) Sovremennyi kinematograficheskii anekdot v usloviiakh setevoi kommunikatsii. In: Pervyi Vserossiiskii kongress fol'kloristov. Sbornik dokladov. Moscow, Gosudarstvennyi respublikanskii tsentr russkogo fol'klora. 440 p. Pp. 307-317. (In Russ.).

Rybakov, Ia. (2016) Studenty ne smogli otlichit' konsul'tatsiiu iskusstvennogo intellekta ot assistenta professor. Life.ru, 10 May [online] Available at: https://life.ru/наука/407510/studienty_nie_ 
smoghli_otlichit_konsultatsiiu_iskusstviennogho_intielliekta_ot_assistienta_profiessora (access date: 12.06 .2017$)$. (In Russ.).

Svas'ian, K. A. (1987) Fenomenologicheskoe poznanie. Erevan, Izd-vo AN Armianskoi ASSR. 199 p. (In Russ.).

Fedotova, V. G. (2000) Informatsionnoe obshchestvo i knigi dlia elit i mass. In: Obshchestvo i kniga: Ot Gutenberga do Interneta / ed. by A. P. Koroleva. Moscow, Traditsiia. 279 p. Pp. 222-234. (In Russ.).

Fridman, Dzh. (2011) Sleduiushchie 10 let : transl. from Engl. Moscow, Eksmo. 320 p. (In Russ.).

Fuko, M. (1996) Volia k istine: po tu storonu znaniia, vlasti i seksual'nosti. Raboty raznykh let : transl. from Fr. Moscow, Kastal'. 448 p. (In Russ.).

McLuhan, M. (1967) The Guttenberg Galaxy: The Making of Typographic Man. Toronto.

McLuhan, M., Hutchon, K. and McLuhan, E. (1977) City as Classroom: Understanding Language and Media. The Book Society of Canada Limited.

Robertson, R. (1992) Globalization: Social Theory and Global Culture. SAGE. 211 p.

Submission date: 15.05 .2017$.

Костина Анна Владимировна - доктор философских наук, доктор культурологии, профессор, заведующий кафедрой философии, культурологии и политологии, декан факультета культуры и искусства Московского гуманитарного университета. Адрес: 111395, Россия, г. Москва, ул. Юности, д. 5. Тел.: +7 (499) 374-61-81. Эл. адрес: Anna_Kostina @inbox.ru

Kostina Anna Vladimirovna, Doctor of Philosophy, Doctor of Culturology, Professor, Head, Department of Philosophy, Culturology and Politology; Dean, Faculty of Culture and Arts, Moscow University for the Humanities. Postal address: 5, Yunosti St., Moscow, Russian Federation 111395. Tel.: +7 (499) 374-61-81. E-mail: Anna_Kostina @inbox.ru

DOI10.17805/zpu.2017.4.9

\title{
Интерпретация смысла истории: событие как культурный артефакт
}

\author{
А. Я. ФЛИЕР \\ РОССИЙСКИЙ НАУЧНО-ИССЛЕДОВАТЕЛЬСКИЙ ИНСТИТУТ КУЛЬТУРНОГО \\ И ПРИРОДНОГО НАСЛЕДИЯ ИМ. Д. С. ЛИХАЧЕВА
}

В статье разворачивается авторская гипотеза о том, что все исторические события являются, по существу, культурными артефактами и могут быть исследованы и реинтерпретированы культурологией в соответствующем ракурсе (параллельно с собственно историческим анализом), что позволит глубже и полнее понять культурную обусловленность социальной активности человека и детерминированность его поведения культурным контекстом. В этом заключаются практическая актуальность и научная новизна статьи.

Событийная история исследует в основном динамические события социальной реальности и дает им по возможности рациональные объяснения, а антропология истории исследует устойчивые исторические состояния, т. е., по существу, культуру данного общества, и дает им объяснения, основанные на культурно-архетипических проявлениях общественного сознания. Это проявления культурной изменчивости и культурной устойчивости исторической культуры данного общества.

Культурная детерминированность этих событий/артефактов связана с тем, что на вызовы истории каждый народ отвечает по-своему, в соответствии с установками своей локаль- 